\title{
Spatial signalling mediated by the transforming growth factor- $\beta$ signalling pathway during tooth formation
}

\author{
Xin-Yu He ${ }^{1,2}$, Ke Sun ${ }^{1,2}$, Ruo-Shi Xu ${ }^{1,2}$, Jia-Li Tan ${ }^{3}$, Cai-Xia Pi ${ }^{1}$, Mian Wan ${ }^{1,2}$, Yi-Ran Peng ${ }^{1,2}$, Ling Ye ${ }^{1,2}$, \\ Li-Wei Zheng ${ }^{1,2}$ and Xue-Dong Zhou ${ }^{1,2}$
}

Tooth development relies on sequential and reciprocal interactions between the epithelial and mesenchymal tissues, and it is continuously regulated by a variety of conserved and specific temporal-spatial signalling pathways. It is well known that suspensions of tooth germ cells can form tooth-like structures after losing the positional information provided by the epithelial and mesenchymal tissues. However, the particular stage in which the tooth germ cells start to form tooth-like structures after losing their positional information remains unclear. In this study, we investigated the reassociation of tooth germ cells suspension from different morphological stages during tooth development and the phosphorylation of Smad2/3 in this process. Four tooth morphological stages were designed in this study. The results showed that tooth germ cells formed odontogenic tissue at embryonic day $(E) 14.5$, which is referred to as the cap stage, and they formed tooth-like structures at E16.5, which is referred to as the early bell stage, and E18.5, which is referred to as the late bell stage. Moreover, the transforming growth factor- $\beta$ signalling pathway might play a role in this process.

International Journal of Oral Science (2016) 8, 199-204; doi:10.1038/ijos.2016.45; published online 16 December 2016

Keywords: positional information; transforming growth factor- $\beta$ signalling pathway; tooth development

\section{INTRODUCTION}

Many elegantly designed studies have shown that tooth development in mammals and other vertebrates is the result of tightly regulated interactions between the dental epithelium and the dental mesenchyme. ${ }^{1-3}$ Epithelium-mesenchyme-based tissueengineering approaches for creating artificial teeth are urgently needed. Numerous molecular and cellular studies have established that the dental epithelium and mesenchyme can form tooth-like tissues. $^{4-5}$ Furthermore, the recombination of either intact, primordial epithelial and mesenchymal tissues or their cell suspensions can form tooth-like tissues. The dissociated tissues from the third molar tooth buds of pigs can recombine to form both dentin and enamel. ${ }^{6}$ Cell suspensions harvested from the tooth buds of embryonic day (E) 14.5 mice and seeded onto collagen scaffolds can also form functional teeth. ${ }^{7-8}$ In addition to embryonic tooth bud suspensions, postnatal tooth buds can also form tooth-like tissues. ${ }^{9}$

The transforming growth factor (TGF)- $\beta$ signalling pathway plays an important role in a broad range of cellular processes. Genetically modified mouse models have confirmed that cell-autonomous TGF- $\beta$ signalling is required for tooth formation. ${ }^{10}$ Recent studies have suggested that the TGF- $\beta$ signalling pathway is involved in tooth root development ${ }^{11}$ and alveolar bone osteogenesis. ${ }^{12}$ However, whether the TGF- $\beta$ pathway participates in the formation of bioengineered teeth remains unknown.

To date, the vast majority of successful tooth recombination studies have used intact dental tissues or suspensions of dental tissues. Although extremely informative, these studies have not identified the stage in which the tooth germ cells can form toothlike structures after the loss of positional information from the epithelial and mesenchymal tissues. To overcome this obstacle, we examined single-cell suspensions from different morphological stages and compared them with untreated tooth germ. Furthermore, we investigated the activation of the TGF- $\beta$ signalling pathway by examining the phosphorylation of Smad2/3. Our results demonstrated that single cells from tooth germ formed odontogenic tissue at E14.5, the cap stage, and formed tooth-like structures at E16.5 and E18.5, the bell stage. Moreover, the TGF- $\beta$ signalling pathway might be one of the spatial signals involved in tooth formation.

\footnotetext{
${ }^{1}$ State Key Laboratory of Oral Diseases, West China Hospital of Stomatology, Sichuan University, Chengdu, China; ${ }^{2}$ West China School of Stomatology, Sichuan University, Chengdu, China and ${ }^{3}$ Guanghua School of Stomatology, Hospital of Stomatology, Department of Endodontics, Guangdong Provincial Key Laboratory of Stomatology, Sun Yat-sen University, Guangzhou, China

Correspondence: Professor LW Zheng, State Key Laboratory of Oral Diseases, West China Hospital of Stomatology, Sichuan University, No. 14 Section 3 , Renmin South Road, Chengdu 610041, China

E-mail: liwei.zheng@scu.edu.cn

Professor XD Zhou, State Key Laboratory of Oral Diseases, West China Hospital of Stomatology, Sichuan University, No. 14 Section 3, Renmin South Road, Chengdu 610041, China E-mail: zhouxd@scu.edu.cn

Accepted 23 August 2016
} 


\section{MATERIALS AND METHODS}

Isolation and preparation of tooth germ from foetal rats

All experiments involving the use of animals were reviewed and approved by the Chengdu Dossy Biological Technology. All tissues were collected in accordance with the guidelines issued by Sichuan University. The study and consent procedures were approved by the ethical committees of the West China School of Stomatology, Sichuan University and the State Key Laboratory of Oral Diseases. Pregnant rats were killed with excessive anaesthesia, and the E13.5-E18.5 rats were harvested and sanitized with $1000 \mathrm{U} \cdot \mathrm{mL}^{-1}$ penicillin and $1 \mathrm{mg} \cdot \mathrm{mL}^{-1}$ streptomycin. The first molar tooth germs were carefully dissociated from the prepared mandibles and washed in phosphate-buffered saline (PBS) with $100 \mathrm{U} \cdot \mathrm{mL}^{-1}$ penicillin and $0.1 \mathrm{mg} \cdot \mathrm{mL}^{-1}$ streptomycin.

\section{Preparation of single-cell suspensions}

All cells were prepared as previously described. ${ }^{7}$ Briefly, the first molar tooth germs were carefully harvested from the mandibles of E13.5-E18.5 rats. The tooth germs were then individually minced into $<1 \mathrm{~mm}^{3}$ pieces, washed in PBS, enzymatically digested with $0.3 \mathrm{mg} \cdot \mathrm{mL}^{-1}$ of type I collagenase (17100-017; Gibco, Grand Island, NY, USA) and $0.4 \mathrm{mg} \cdot \mathrm{mL}^{-1}$ of Dispase I (17105-041; Gibco, Grand Island, NY, USA) for $45 \mathrm{~min}$ at $37^{\circ} \mathrm{C}$, and gently dissociated by trituration. Cells were washed and filtered using a sterile Falcon 40-micron cell strainer (Corning, Tewksbury, MA, USA) to generate single-cell suspensions.
Preparation of reassociated constructs and transplantation under renal capsules

The cell-loaded constructs of single-cell suspensions consisted of $1.0 \times 10^{6}$ cells suspended in $50 \mu \mathrm{L}$ of $1 \mathrm{mg} \cdot \mathrm{mL}^{-1}$ of collagen type I $\left(2.0 \times 10^{4}\right.$ cells per $\left.\mu \mathrm{L}\right)$. The constructs were suspended in collagen and gelled at $37^{\circ} \mathrm{C}$ for $1 \mathrm{~h}$ before being transplanted under the renal capsules. Laparotomies were performed on rats, and the reassociated constructs were implanted in the renal capsules as previously described. ${ }^{13-14}$ The numbers of the single-cell suspension constructs were as follows: E13.5(4/6), E14.5(4/5), E16.5(4/6), and E18.5(5/8). The numbers of the tooth germ transplants were as follows: E13.5 (3/3), E14.5(3/4), E16.5(3/4), and E18.5(3/3).

Haematoxylin and eosin staining, Masson's trichrome staining and immunohistochemistry staining of reassociation constructs

Paraffin-embedded samples were sectioned at a thickness of $5 \mu \mathrm{m}$. Selected sections were then stained with haematoxylin and eosin (H\&E) and analysed under bright-field microscopy (BX53; Olympus, Tokyo, Japan). For Masson's trichrome staining, we used Weigert's iron haematoxylin, Biebrich scarlet-acid fuchsin and aniline blue. Immunohistochemical analyses were performed on selected sections of each construct using a tooth-specific antibody against amelogenin (sc32892; Santa Cruz Biotechnology, Paso Robles, CA, USA), a TGF- $\beta$ pathway-specific antibody against p-Smad2/3 (sc-11769; Santa Cruz Biotechnology, Paso Robles, CA, USA) and an antibody against

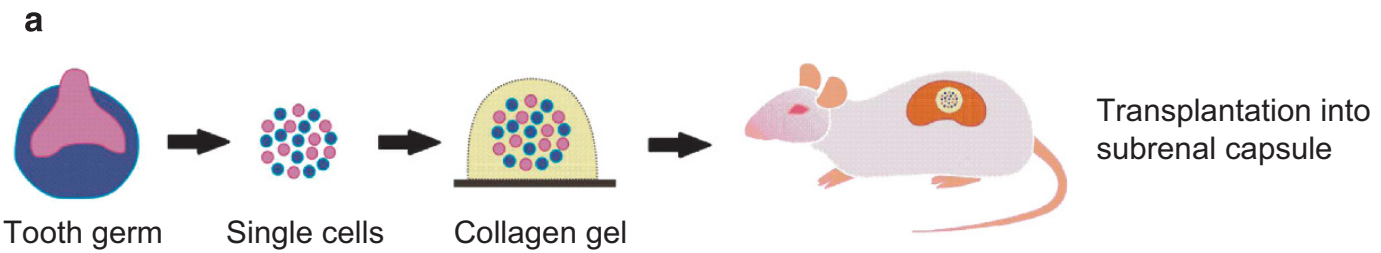

E13.5
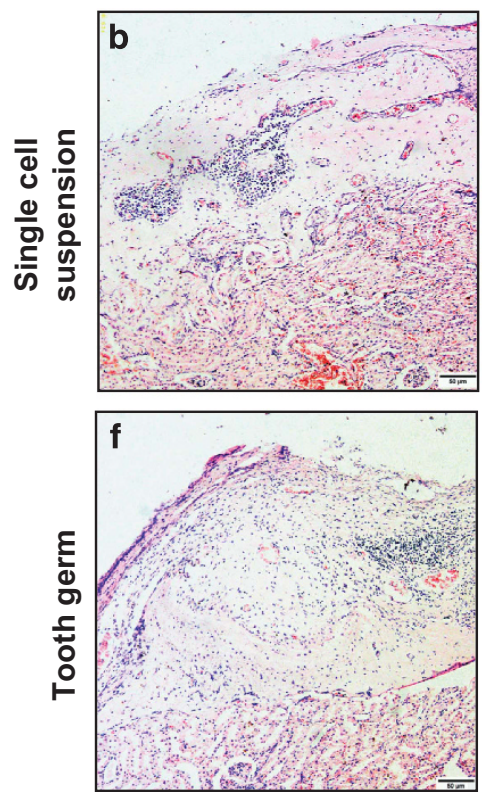

E14.5
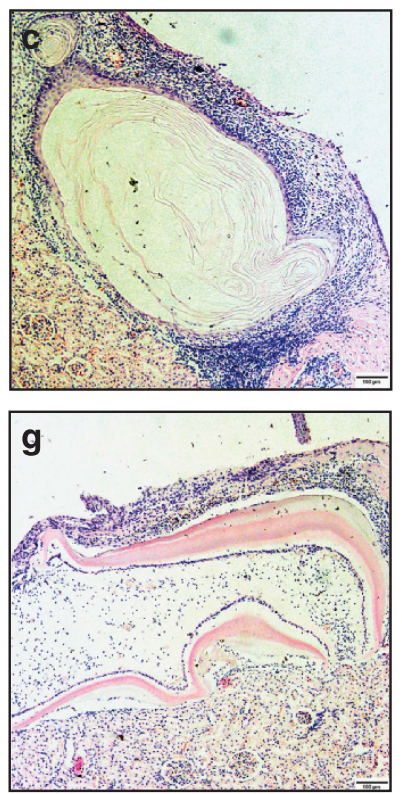

E16.5
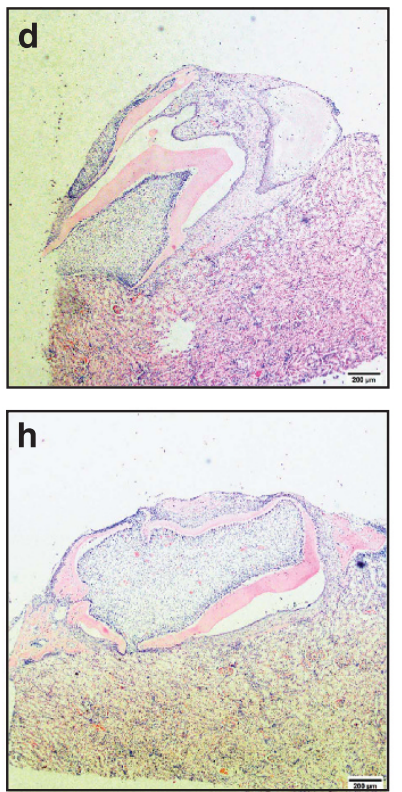

E18.5
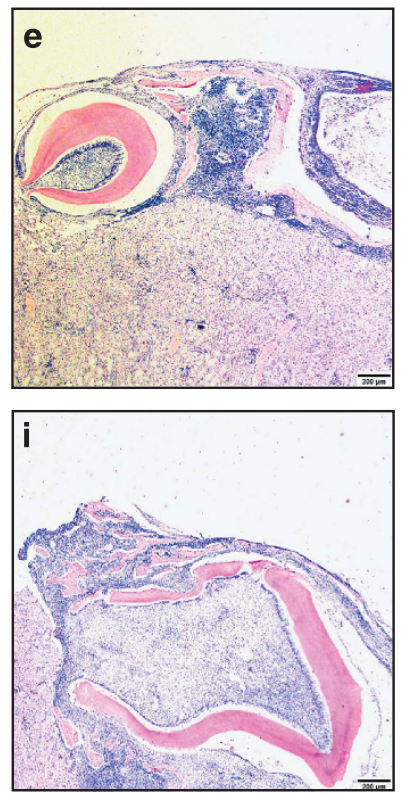

Figure 1 Morphological analysis of the transplants. (a) Schematic diagram of the reaggregated system. (b) Recombination from an E13.5 single-cell suspensions appeared as disordered tissue on an H\&E-stained section. (c) At E14.5, the single-cell suspensions formed several epithelial pearls. (d, e) At E16.5 and E18.5, the single-cell suspensions exhibited tooth-like tissue. (f) At E13.5, the tooth germ transplants formed a boundary between the epithelial and mesenchymal tissue. (g-i) And at E14.5, E16.5 and E18.5, the tooth germ formed tooth-like tissue. Scale bar for b and f: $50 \mu \mathrm{m}$; for $\mathbf{c}$ and $\mathbf{g}$ : $100 \mu \mathrm{m}$; and for d, e, h and i: $200 \mu \mathrm{m}$. E, embryonic day. 
smad2/3 (NBP1-19520; Novus Biologicals, Littleton, CO, USA). For immunohistochemistry (IHC), all sections were incubated with a biotinylated secondary antibody, stained using the R\&D HRP-DAB staining kit (R\&D Systems, Minneapolis, MN, USA) and counterstained with haematoxylin. Processed sections were dehydrated through a series of graded ethanol baths, sealed with Permount (Thermo Fisher Scientific, Waltham, MA, USA), and analysed using bright-field microscopy. Photographs were obtained with a digital camera and manipulated using Adobe Photoshop.

\section{Statistical analysis}

Significance $(P<0.05)$ was determined using the unpaired Student's $t$-test and analysed using the SPSS 16.0 software package.

\section{RESULTS}

\section{Morphological characterization of the transplants}

All cells were prepared and transplanted into the renal capsules as described in the Materials and Methods section (Figure 1a). After sample collection, all transplants were separated from the host renal capsules, embedded in paraffin and sectioned. Morphological analysis by HE staining was performed to examine the stage in which the singlecell suspensions started to form tooth-like structures. The reassociation of the E13.5 single-cell suspensions was characterized by disordered tissue that failed to organize (Figure 1b). At E14.5, the single-cell suspensions had formed several epithelial pearls, but no tooth-like structures were observed (Figure 1c). At E16.5 and E18.5, the single-cell suspensions had formed tooth-like tissues (Figure $2 \mathrm{~d}$ and 2e). The E13.5 tooth germ transplants presented clear boundaries between the epithelial tissues and the mesenchymal tissues (Figure 1f), similar to the results of other studies. ${ }^{13}$ At E14.5, E16.5 and E18.5, the transplants formed tooth-like tissues, including dental pulp and dentin, and exhibited apical constriction (Figure 1g-1i). This finding indicates that E16.5 might be the earliest stage in which tooth-like structures can form after the loss of positional information from the epithelial and mesenchymal tissues.

\section{Histological characterization of the transplants}

Masson's trichrome staining showed that there was no boundary between the epithelial tissue and mesenchymal tissue in the E13.5 single-cell suspensions (Figure 2a). Epithelial pearls were observed in both the E14.5 and E16.5 single-cell suspensions (Figure $2 \mathrm{~b}$ and $2 \mathrm{c}$ ). In addition, singlecell suspensions from E16.5 exhibited pulp tissue, dentin and apical
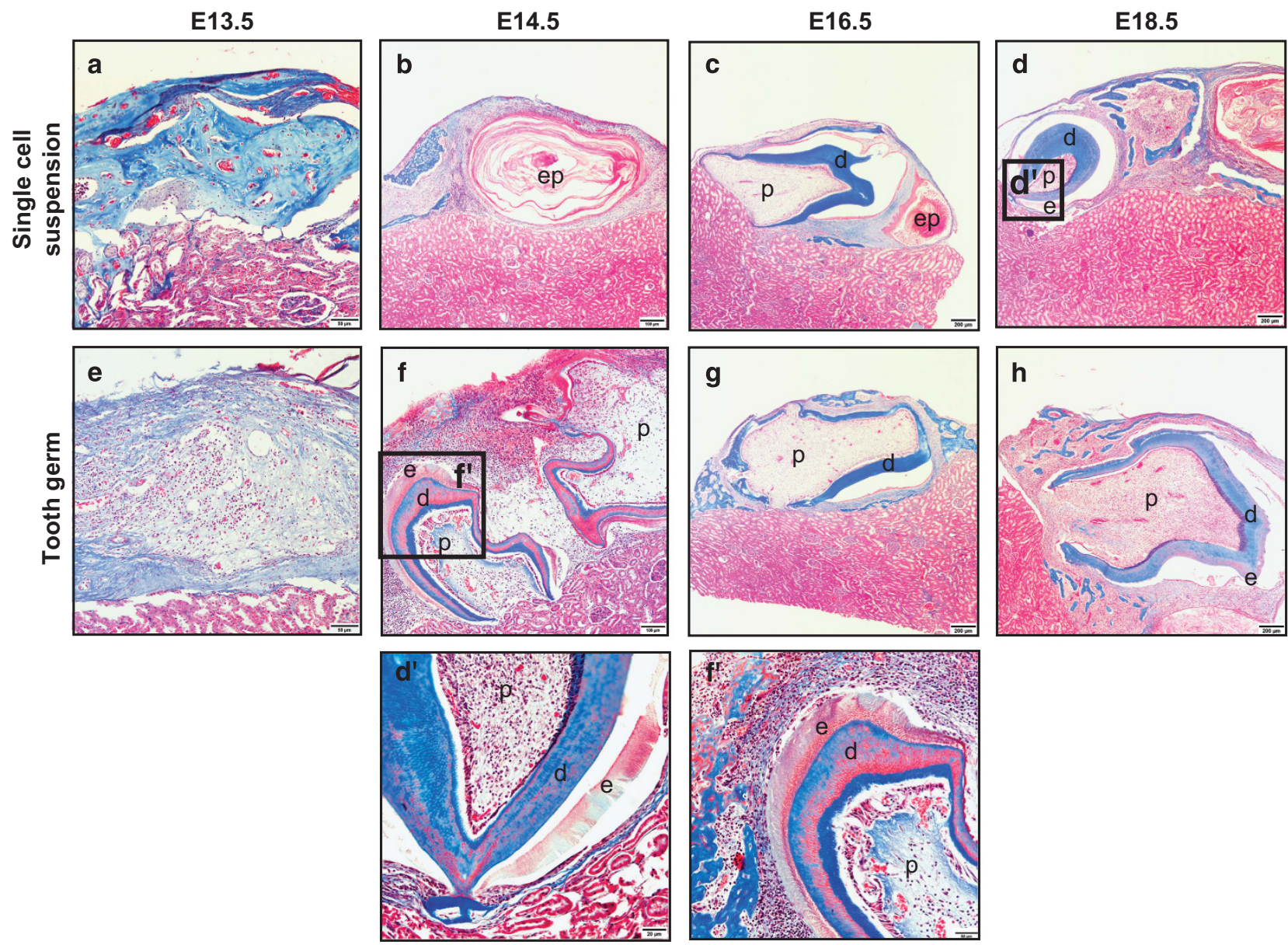

Figure 2 Histological analysis of transplants. (a) At E13.5, the single-cell suspensions had no tissue boundary. (b) At E14.5, the single-cell suspensions formed several epithelial pearls. (c) At E16.5, pulp tissue, dentin and apical constriction were observed, but no enamel was observed. (d) At E18.5, the single-cell suspensions started to form immature enamel tissue. (e) The tooth germ transplants formed a boundary between the epithelial and mesenchymal tissue. (f, h) Pulp tissue, dentin, apical constriction and immature enamel tissue were observed in both the E14.5 and E18.5 suspensions, (g) but no enamel was observed in the E16.5 suspensions. Scale bar for a and e: $50 \mu \mathrm{m}$; for $\mathbf{b}$ and f: $100 \mu \mathrm{m}$; for c, d, $\mathbf{g}$ and $\mathbf{h}: 200 \mu \mathrm{m}$; for d': $20 \mu \mathrm{m}$; and for f': $50 \mu \mathrm{m}$. E, embryonic day. 
constriction, but no enamel tissue. We also observed immature enamel tissue adjacent to the dentin at E18.5 (Figure 2d and 2d'). The tooth germ transplants started to exhibit clear histological layers at E14.5 (Figure 2e). We observed pulp tissue, dentin, apical constriction and immature enamel tissue in both the E14.5 and E18.5 transplants (Figure 2f, $2 \mathrm{f}$ and $2 \mathrm{~h}$ ), but no enamel was observed in the E16.5 transplants.

\section{Immunocytochemical analysis of the transplants}

We examined the expression of amelogenin using IHC. The single-cell suspensions started to exhibit positive staining at E18.5 (Figure 3d), and it closely resembled decalcified enamel adjacent to the dentin. The tooth germ transplants revealed a clear epithelial-mesenchymal boundary at E13.5 (Figure 3e), and amelogenin-positive staining was also detected in the matrix at E14.5 and E18.5 (Figure $3 \mathrm{f}$ and $3 \mathrm{~h}$ ).

\section{TGF- $\beta$ signalling in transplants}

In response to activation of the TGF- $\beta$ signalling pathway, Smad 2 and Smad3 are phosphorylated and translocated from the cytosol to the nucleus. ${ }^{15-16}$ To investigate whether the TGF- $\beta$ signalling pathway was involved in the reassociation process, we examined the phosphorylation of Smad2/3 using IHC. The rate of positively stained cells in the single-cell suspensions from E16.5 was higher than in the other stages (Figure $4 \mathrm{f}-4 \mathrm{j}$ ). However, the rate of positively stained cells in the tooth germ transplants was the same at E13.5, E14.5 and E16.5 (Figure 4p-4r). In addition, the rate of positively stained cells at E18.5 was higher than the other groups (Figure $4 \mathrm{~s}$ and $4 \mathrm{t}$ ). We also examined the expression of nonphosphorylated $S \operatorname{mad} 2 / 3$ as a control using IHC (Figure $4 \mathrm{a}-4 \mathrm{e}$ and $4 \mathrm{k}-4 \mathrm{o}$ ). This finding indicates that the TGF- $\beta$ signalling pathway may play a role in tooth development.

\section{DISCUSSION}

In this study, we investigated the stages at which tooth germ cell suspensions can form tooth-like tissues after losing their positional information. As other studies have reported, ${ }^{8}$ we showed that successful odontogenic tissue (that is, epithelial pearls) formed during the cap stage (E14.5), while tooth-like tissues, dentin and apical constriction started to develop during the early bell stage (E16.5). In addition, enamel appeared in the late bell stage (E18.5). These findings suggest that single-cell suspensions of later morphological stages may form more mature, tooth-like structures. Moreover, the phosphorylation level of $S \operatorname{mad} 2 / 3$ was higher in both single-cell suspensions at E16.5 and tooth germ transplants at E18.5. These results indicate that the TGF- $\beta$ pathway may be involved in this tooth development.

It is possible to bioengineer teeth from embryonic tooth bud cells, ${ }^{17-18}$ and even postnatal tooth buds can form tooth-like tissues. ${ }^{9}$ In previous studies, the epithelium and mesenchyme were collected and suspended individually before being reassociated, and the relative orientation of the epithelium and mesenchyme was largely maintained. The results showed that the reassociation of E14 dental epithelium and dental mesenchyme single-cell suspensions resulted in the formation of a bioengineered tooth unit that included the developing root, differentiated odontoblasts, cementum and periodontal ligament fibroblasts, with the development of the root surface and newly formed bone occurring after in vivo transplantation. ${ }^{19}$ An analysis of 12-week-old implant tissue from dissociated rat tooth bud cells that were 4 days postnatal also demonstrated that suspensions from tooth buds can reliably generate bioengineered tooth tissue with roots and bones. ${ }^{4}$ Our study involved tooth buds that were suspended as complete units, and the positional information was completely disrupted. In this situation, the tooth bud can form a tooth-like structure.

Previous studies have suggested that the SHH, FGF, NOTCH, BMP and WNT signalling pathways are involved in the regulation of tooth histogenesis, morphogenesis and cell differentiation. ${ }^{20-22}$ The TGF- $\beta$ pathway is involved in many cellular processes in both mature
E13.5
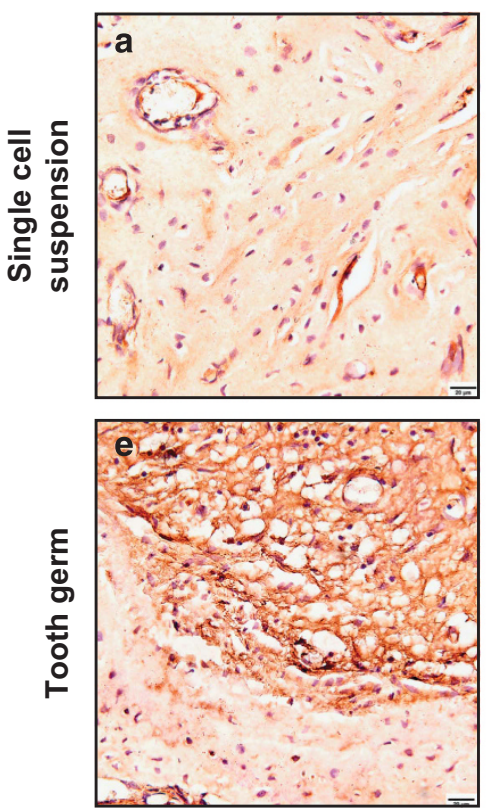

E14.5
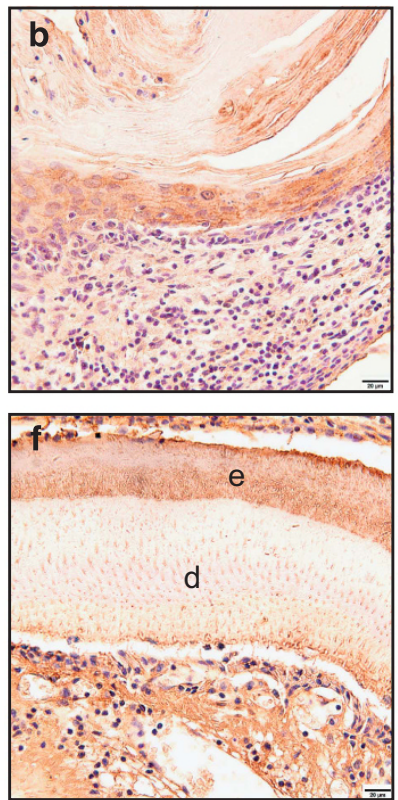

E16.5
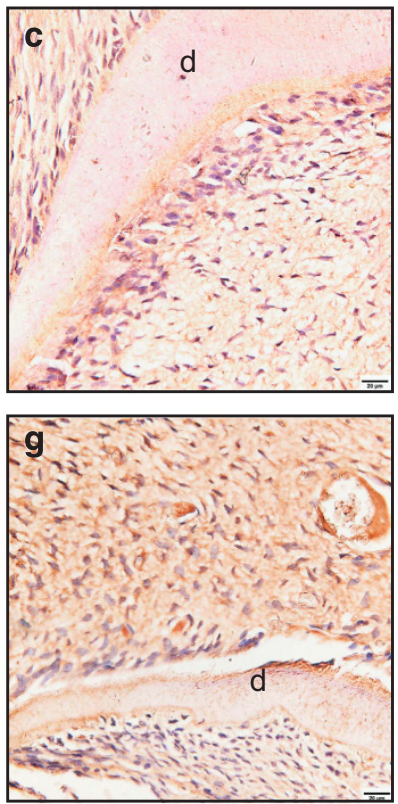

E18.5
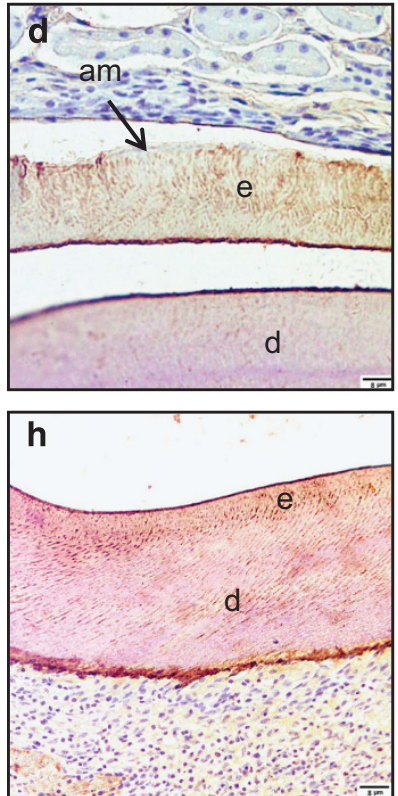

Figure 3 Immunohistochemical analysis of amelogenin expression. (a-c) At E13.5, E14.5 E16.5, the single-cell suspensions has no obvious positive staining of amelogenin. (d) The single-cell suspensions started to exhibit positive staining at E18.5. (f, $\mathbf{h}$ ) The tooth germ transplants revealed a clear epithelial-mesenchymal boundary at E13.5. (f, h) The amelogenin-positive staining could also be detected at E14.5 and E18.5. (g) However, there has no obvious positive staining at E16.5. Scale bar for $\mathbf{a}-\mathbf{g}: 20 \mu \mathrm{m}$ and for $\mathbf{d}$ and $\mathbf{h}: 8 \mu \mathrm{m}$. E, embryonic day. 

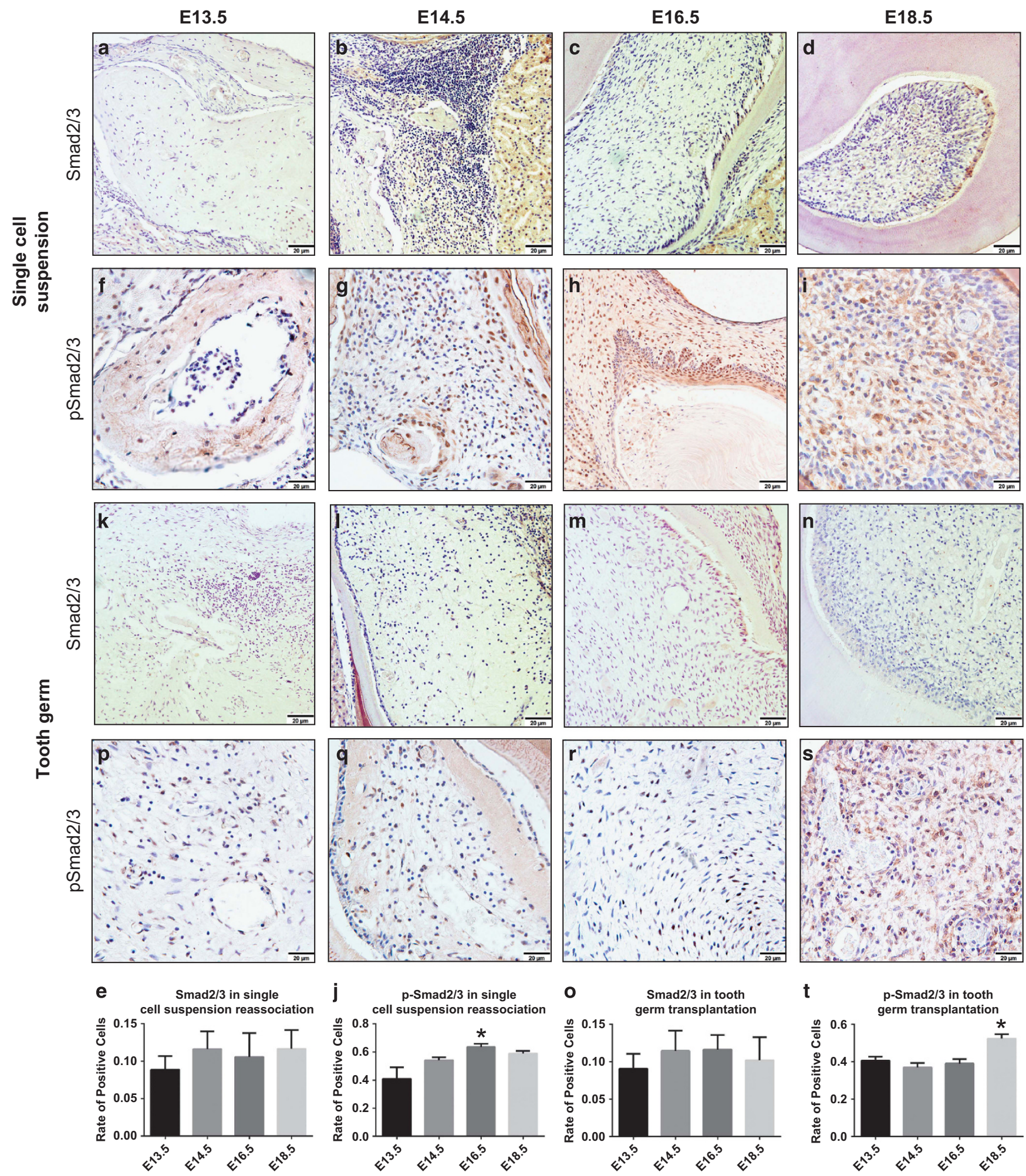

Figure 4 Immunohistochemical analysis of the expression and phosphorylation of Smad2/3. The Smad2/3- and p-Smad2/3-positive cells were counted in each view, and the rate of positively stained cells was determined. (a-e, $\mathbf{k}-\mathbf{0}$ ). Smad2/3 (stained brown) expression was analysed in the cell cytoplasm. The rate of cells positively stained for Smad2/3 was the same across all of these stages. Scale bar: $20 \mu \mathrm{m}$. (f-j) p-Smad2/3 expression (brown staining) was analysed in the cell nucleus. The single-cell suspensions had a higher rate of positive cells at E16.5. (p-t) However, the tooth germ had a higher rate of positive cells at E18.5. All data are presented as the mean \pm standard deviation, ${ }^{*} P<0.05$ by unpaired $t$-test. Scale bar: $20 \mu \mathrm{m}$. E, embryonic day. 
organisms and embryos, including cell proliferation, cell differentiation and other cellular functions. ${ }^{23}$ There is also extensive crosstalk between the TGF- $\beta$ pathway and other signalling pathways, such as BMP. ${ }^{24-26}$ Although few studies have addressed the involvement of the TGF- $\beta$ pathway in dental development, some evidence suggests that TGF- $\beta$ plays a role in this process. Tgfbr2-deficient mice exhibited malformed incisors with wavy mineralized structures, and this phenotype may be caused by an upregulation of Wnt5a expression and a downregulation of Fgf3/10 expression in the mesenchyme. ${ }^{27}$ Moreover, Hertwig's epithelial root sheath cells are strongly positive for TGF- $\beta 1$. In addition, positive staining for $\mathrm{p}-\mathrm{Smad} 2 / 3$ has been observed in bone and periodontal ligaments. ${ }^{28}$ Taken together, our results and the above studies indicate that the TGF- $\beta$ signalling pathway may play a role in tooth formation.

The ultimate goal of bioengineering studies is to develop regenerative therapies that will restore lost or damaged teeth. ${ }^{29-30}$ Previous studies of three-dimensional organ cultures revealed that embryonic tooth cells can generate bioengineered organs that are fully functional. In our study, we found that single tooth germ cells started to form tooth-like structures at the early bell stage (E16.5) after losing their positional information. Further studies using seed cells may confirm our study findings and result in a greater understanding of the clinical applications for bioengineered teeth in regenerative therapy.

\section{CONCLUSION}

This study revealed the following important findings: after the loss of tissue positional information, single-cell suspensions of tooth germ cells formed epithelial pearls at the cap stage (E14.5) and formed tooth-like structures at E16.5 and E18.5. In addition, the TGF-beta signalling pathway might play a role in this process.

\section{ACKNOWLEDGEMENTS}

We would like to thank the members of the Dental Development Laboratory for their critical expert advice regarding the results presented in this study. This work was supported by NSFC grant 81371136 to Xue-Dong Zhou, NSFC grant 81470711 to Li-Wei Zheng and grant 2015TD0011 to Ling Ye.

1 Peng L, Ye L, Zhou XD. Mesenchymal stem cells and tooth engineering. Int J Oral Sci 2009; 1(1): 6-12.

2 Lumsden AG. Spatial organization of the epithelium and the role of neural crest cells in the initiation of the mammalian tooth germ. Development 1998; 103(Suppl): 155-169.

3 Thesleff I, Jernvall J. The enamel knot: a putative signaling center regulating tooth development. Cold Spring Harb Symp Quant Biol 1997; 62: 257-267.

4 Duailibi MT, Duailibi SE, Young CS et al. Bioengineered teeth from cultured rat tooth bud cells. J Dent Res 2004; 83(7): 523-528.

5 Zhang W, Vázquez B, Yelick PC. Bioengineered post-natal recombinant tooth bud models. J Tissue Eng Regen Med 2014. doi:10.1002/term.1962.

6 Young CS, Terada S, Vacanti JP et al. Tissue engineering of complex tooth structures on biodegradable polymer scaffolds. J Dent Res 2002; 81(10): 695-700.
7 Nakao K, Morita R, Saji Y et al. The development of a bioengineered organ germ method. Nat Methods 2007; 4 (3): 227-230.

8 Oshima M, Mizuno M, Imamura $\mathrm{A}$ et al. Functional tooth regeneration using a bioengineered tooth unit as a mature organ replacement regenerative therapy. PLoS One 2011; 6(7): e21531.

9 Honda MJ, Fong $\mathrm{H}$, Iwatsuki S et al. Tooth-forming potential in embryonic and postnatal tooth bud cells. Med Mol Morphol 2008; 41(4): 183-192.

10 Ito Y, Yeo JY, Chytil A et al. Conditional inactivation of Tgfbr2 in cranial neural crest causes cleft palate and calvaria defects. Development 2003; 130(21): 5269-5280.

11 Huang XF, Chai Y. Molecular regulatory mechanism of tooth root development. Int J Oral Sci 2012; 4(4): 177-181.

12 Liu C, Wu Z, Sun HC. The effect of simvastatin on mRNA expression of transforming growth factor-beta1, bone morphogenetic protein-2 and vascular endothelial growth factor in tooth extraction socket. Int J Oral Sci 2009; 1(2): 90-98.

13 Ohazama A, Modino SA, Miletich I et al. Stem-cell-based tissue engineering of murine teeth. J Dent Res 2004; 83(7): 518-522.

14 Yamamoto H, Kim EJ, Cho SW et al. Analysis of tooth formation by reaggregated dental mesenchyme from mouse embryo. J Electron Microsc 2003; 52(6): 559-566.

15 Rahman MS, Akhtar N, Jamil HM et al. TGF- $\beta /$ BMP signaling and other molecular events: regulation of osteoblastogenesis and bone formation. Bone Res 2015; 3:15005.

16 Shen J, Li S, Chen D. TGF- $\beta$ signaling and the development of osteoarthritis. Bone Res 2014; 2:14002

17 Henkel J, Woodruff MA, Epari DR et al. Bone regeneration based on tissue engineering conceptions - a 21st century perspective. Bone Res 2013; 1(3): 216-248.

18 Gong T, Xie J, Liao J et al. Nanomaterials and bone regeneration. Bone Res 2015; $3: 15029$.

19 Iwatsuki S, Honda MJ, Harada $\mathrm{H}$ et al. Cell proliferation in teeth reconstructed from dispersed cells of embryonic tooth germs in a three-dimensional scaffold. Eur J Oral Sci 2006; 114(4): 310-317.

20 Thesleff I, Sharpe P. Signaling networks regulating dental development. Mech Dev 1997; 67(2): 111-123.

21 Kohn A, Rutkowski TP, Liu Z et al. Notch signaling controls chondrocyte hypertrophy via indirect regulation of Sox9. Bone Res 2015; 3: 15021.

22 Joeng KS, Long F. Wnt7b can replace Ihh to induce hypertrophic cartilage vascularization but not osteoblast differentiation during endochondral bone development. Bone Res 2014; 2: 14004.

23 Lee MJ, Kim EJ, Otsu K et al. Sox2 contributes to tooth development via Wnt signaling. Cell Tissue Res 2016; 365(1): 77-84.

24 Keller B, Yang T, Chen $Y$ et al. Interaction of TGF- $\beta$ and BMP signaling pathways during chondrogenesis. PLoS One 2011; 6(1): e16421.

25 Poorgholi Belverdi M, Krause C, Guzman A et al. Comprehensive analysis of TGF- $\beta$ and BMP receptor interactions. Eur J Cell Biol 2012; 91(4): 287-293.

26 Luo T, Cui S, Bian C et al. Crosstalk between TGF- $\beta$ /Smad3 and BMP/BMPR2 signaling pathways via miR-17-92 cluster in carotid artery restenosis. Mol Cell Biochem 2014; 389(1/2): 169-176.

27 Yang G, Zhou J, Teng Y et al. Mesenchymal TGF- $\beta$ signaling orchestrates dental epithelial stem cell homeostasis through Wnt signaling. Stem Cells 2014; 32(11): 2939-2948.

$28 \mathrm{Li} \mathrm{S}, \mathrm{Ge} \mathrm{S}$, Yang P. Immunohistochemical localization of connective tissue growth factor, transforming growth factor-beta 1 and phosphorylated-smad2/3 in the developing periodontium of rats. J Periodontal Res 2014; 49(5): 624-633.

29 Duailibi SE, Duailibi MT, Zhang W et al. Bioengineered dental tissues grown in the rat jaw. J Dent Res 2008; 87(8): 745-750.

$30 \mathrm{Hu}$ B, Nadiri A, Kuchler-Bopp S et al. Tissue engineering of tooth crown, root, and periodontium. Tissue Eng 2006; 12(8): 2069-2075.

This work is licensed under a Creative Commons Attribution 4.0 International License. The images or other third party material in this article are included in the article's Creative Commons license, unless indicated otherwise in the are included in the article's Creative Commons license, unless indicated otherwise in the
credit line; if the material is not included under the Creative Commons license, users will need to obtain permission from the license holder to reproduce the material. To view a copy of this license, visit http://creativecommons.org/licenses/by/4.0/

(C) The Author(s) 2016 